\title{
Estimation of breeding probability can make monitoring data more revealing: a case study of amphibians
}

\author{
Sam S. Cruickshank (iD,${ }^{1,4}$ Ariel Bergamini (D) ${ }^{1}$ and Benedikt R. Schmidt (iD) 2,3,5 \\ ${ }^{1}$ Swiss Federal Institute for Forest, Snow and Landscape Research WSL, Zürcherstrasse 111, Birmensdorf 8093 Switzerland \\ ${ }^{2}$ Info Fauna Karch, UniMail, Bâtiment G, Bellevaux 51, Neuchâtel 2000 Switzerland \\ ${ }^{3}$ Institut für Evolutionsbiologie und Umweltwissenschaften, Universität Zürich, Winterthurerstrasse 190, Zürich 8057 Switzerland
}

Citation: Cruickshank, S. S., A. Bergamini, and B. R. Schmidt. 2021. Estimation of breeding probability can make monitoring data more revealing: a case study of amphibians. Ecological Applications 31(6): e02357. 10.1002/eap.2357

\begin{abstract}
Monitoring programs serve to detect trends in the distribution and abundance of species. To do so, monitoring programs often use static state variables. Dynamic state variables that describe population dynamics might be more valuable because they allow for a mechanistic understanding of the processes that lead to population trends. We fit multistate occupancy models to data from a country-wide multispecies amphibian occupancy monitoring program and estimated occupancy and breeding probabilities. If breeding probabilities are determinants of occupancy dynamics, then they may serve in monitoring programs as state variables that describe dynamic processes. The results showed that breeding probabilities were low and that a large proportion of the populations had to be considered to be non-breeding populations (i.e., populations where adults are present but no breeding occurs). For some species, the majority of populations were non-breeding populations. We found that non-breeding populations have lower persistence probabilities than populations where breeding occurs. Breeding probabilities may thus explain trends in occupancy but they might also explain other ecological phenomena, such as the success of invasive species, which had high breeding probabilities. Signs of breeding, i.e., the presence of eggs and larvae, were often hard to detect. Importantly, non-breeding populations also had low detection probabilities, perhaps because they had lower abundances. We suggest that monitoring programs should invest more in the detection of life history stages indicative of breeding, and also into the detection of nonbreeding populations. We conclude that breeding probability should be used as a state variable in monitoring programs because it can lead to deeper insights into the processes driving occupancy dynamics.
\end{abstract}

Key words: amphibian; breeding probability; monitoring; occupancy; population dynamics.

\section{INTRODUCTION}

Population declines are the first step toward the loss of species, both locally and globally. Therefore, conservation biologists monitor populations to quantify and to explain how and why populations grow and shrink. Customarily, monitoring programs are used to describe changes in the size of animal and plant populations through time (Buckland et al. 2005, Marsh and Trenham 2008, Geijzendorffer et al. 2016). The growth rate of a population, $\lambda$, can be described by the simple ratio of two successive population sizes $\left(N_{t}\right.$; Turchin 1999)

Manuscript received 10 June 2020; revised 17 November 2020; accepted 14 January 2021. Corresponding Editor: Trenton W. J. Garner.

${ }^{4}$ Present address: Swiss National Park, Runatsch 124, Chasté Planta-Wildenberg, 7530 Zernez, Switzerland

${ }^{5}$ E-mail: benedikt.schmidt@uzh.ch

$$
\lambda=N_{t+1} / N_{t} .
$$

The analyses of time-series data can inform about trends in abundance and can lead to valuable insights into the ecology and conservation of species (Inchausti and Halley 2003, Leung et al. 2017). However, such data are less suitable for understanding the processes that lead to population declines because these data contain no information on demographic mechanisms. It is more informative to decompose population growth into its demographic components and to determine how the relative contributions of gains and losses contributes to population trends (Nichols et al. 2000, Bjørnstad and Grenfell 2001). The canonical equation of population ecology decomposes population growth into its demographic components. The equation states that changes in population size $(N)$ through time $(t)$ depend on gains to the population through births and immigration and on the loss of individuals from the populations through death and emigration (Pulliam 1988) 


$$
\begin{aligned}
N_{t+1}= & N_{t}+\text { births }_{t}+\text { immigrants }_{t}-\text { deaths }_{t} \\
& - \text { emigrants }_{t} .
\end{aligned}
$$

There is a consensus among population ecologists that analyses of population dynamics that include an explicit modeling of vital rates and phenotypic traits yield deeper insights into the processes driving population dynamics (Clutton-Brock and Sheldon 2010, Zipkin et al. 2014, Clements and Ozgul 2016, Coulson et al. 2017, Plard et al. 2019) and metapopulation dynamics where vital rates may vary among populations (MacKenzie et al. 2003, Runge et al. 2006, Gurevitch et al. 2016). Similarly, in species distribution modeling, researchers are increasingly aware that although presence/absence or presence-only data may yield predictions of habitat suitability, these predicted suitabilities may not reflect the performance of individuals (Kearney 2006, Thuiller et al. 2014, Unglaub et al. 2018). Modeling the dynamic processes underlying distribution patterns is likely to be more informative than static analyses (Schmidt and Pellet 2005, Keith et al. 2008, Kéry et al. 2013, Yackulic et al. 2015). For example, adding data on vital rates that determine dynamic processes (e.g., data on reproductive performance [births in the equation above]) improved the predictive value of distribution models for conservation (Titeux et al. 2007, Brambilla and Ficetola 2012, Searcy and Shaffer 2016, Bacon et al. 2017). This is perhaps not surprising if we remind ourselves that species may be present in sink habitats where population growth rates $(\lambda)$ are less than 1 , perhaps because there is no successful reproduction (Pulliam 1988, 2000).

Consequently, species monitoring programs that focus on the essential biodiversity variables "species distribution" and "species abundance" (sensu Jetz et al. 2019) may benefit from data on breeding (e.g., anything ranging from the presence of eggs and larval stages to recruitment rates; our operational definition in this study is explained in Methods). To date, however, many species monitoring programs collect data on the abundance, distribution, and richness of species but not breeding (Buckland et al. 2005, Marsh and Trenham 2008, Geijzendorffer et al. 2016). The relevance of a monitoring program for species management can be increased if there are also data on the processes that lead to changes in the distribution or abundance of species (Nichols and Williams 2006, Martin et al. 2009, Green et al. 2013, Schmeller et al. 2018). Data on where breeding occurs and on trends in breeding, for example, in the number of sites with successful reproduction, would be very valuable for species conservation. These kinds of data could lead to a better understanding of the drivers of population change and could lead to more insightful analyses of the effectiveness of conservation actions (Schmidt et al. 2019).

We used data from a nation-wide amphibian monitoring program (Bergamini et al. 2019) to estimate and compare the occurrence of adults and the occurrence of breeding for multiple species. Amphibians are a suitable class for this type of analysis for two reasons. The global decline of amphibians is an ongoing phenomenon (Houlahan et al. 2000, Grant et al. 2016, Leung et al. 2017, Falaschi et al. 2019). While there are many known causes contributing to declines (e.g., pathogens, overharvesting, habitat loss; Stuart et al. 2004, Grant et al. 2016), the demographic processes underlying the declines are not yet sufficiently understood (Marsh and Trenham 2001, Schmidt et al. 2005, Muths et al. 2017). Obviously, the possible lack of successful breeding could be one factor that can contribute to population decline. For example, Vredenburg (2004) showed that frog populations recovered quickly after fish were removed because there was no longer fish predation on larvae. Furthermore, it is well known that successful reproduction does not occur in all years in amphibian populations (Shoop 1974, Bell and Lawton 1975, Sinsch 1992, Greenberg et al. 2017) and that many populations appear to be sink populations without or with little offspring production (i.e., metamorphs; Gill 1978, Sinsch 1992, Hels 2002, Peterman et al. 2018). An increasing number of studies have reported the absence of reproductive stages at sites where adults appear to thrive (Green et al. 2013, Unglaub et al. 2015, Tournier et al. 2017, Gould et al. 2019, Schmidt et al. 2019).

We use multistate occupancy models (Nichols et al. 2007) to estimate both occurrence and breeding probabilities (given occurrence) and the detection probabilities of the species overall and of breeding life stages (i.e., eggs or larvae). We do so for the entire assemblage of pond-breeding amphibians in Switzerland. The estimates can inform the feasibility of monitoring the occurrence of breeding. If the detectability of breeding (i.e., detectability of eggs and tadpoles) is low, then uncertainty will be large and parameter estimates of limited value (Schmidt et al. 2019). Nevertheless, reliable estimates of breeding probability as a state variable in a monitoring program may add value to it because the lack of breeding may be an early warning signal of impending population declines. We discuss the implications of the results for the design of monitoring programs and the conservation biology of amphibians.

\section{Materials AND Methods}

\section{The monitoring program}

We used data collected by the Swiss national monitoring program "Monitoring the Effectiveness of Habitat Conservation in Switzerland" ("Wirkungskontrolle Biotopschutz Schweiz" (WBS); Bergamini et al. 2019; program details available online). ${ }^{6}$ The 240 sites included in the monitoring program are amphibian breeding sites of national importance and were selected by a stratified random procedure from all amphibian breeding sites of

\footnotetext{
${ }^{6}$ https://biotopschutz.wsl.ch/en/index.html
} 
national importance (Schmidt and Zumbach 2019). Sites are visited according to a rotating panel design (McDonald 2003) such that each of the 240 sites is visited once every six years (40 sites visited every year). For our analyses, we used data collected from 2011 to 2016 at 233 of the 240 sites (data from some sites was not available). Monitoring continued after 2016 and we used data from 73 sites that were re-surveyed in 2017 and 2018 to analyze the effects of earlier occupancy status (i.e., absent, present but no breeding, present and breeding) upon population persistence. The sites re-surveyed in 2017 and 2018 were first visited in 2011 and 2012.

Survey protocols for the national program include four visits during the breeding season (March-June) for every site targeted for a visit in a given year. The survey window spans four months in order to include the breeding seasons of all amphibians in the assemblage (Appendix S1: Table S1). Repeated visits to a site allow imperfect detection to be accounted for when estimating site occupancy and breeding probabilities (MacKenzie et al. 2002, Nichols et al. 2007). At each visit, the goal is to detect all species and all life history stages (eggs, larvae, adults, calling males) that are present. Methods include visual encounter surveys, aural surveys and dipnetting (Dodd 2009). Surveys are limited to $1 \mathrm{~h}$, independent of the size of the site. If a site is large, then surveyors are instructed to focus on the areas that seem most suitable for amphibians. In any given year, 16-29 professional herpetologists are given mandates to conduct the surveys; with each person surveying one to four sites. To ensure population closure, we carried out data set filtering following the recommendations of MacKenzie et al. (2002). For each species, we removed survey data from surveys carried out before the first sighting of a species within the year, and after the final sighting within that year.

\section{Statistical analyses}

We used single-season multistate occupancy models to analyze the data (Nichols et al. 2007). Multistate occupancy models estimate the probability that a pond is occupied $(\psi)$ and the probability that breeding occurs (given occupancy; $r$ ). The three (latent) states were: (1) species absent $(1-\psi),(2)$ species present but no breeding $(\psi(1-r))$, and (3) species present and breeding $(\psi r)$. We used the estimates of occurrence $(\psi)$ and breeding probability $(r)$ to estimate the number of sites with breeding and non-breeding populations.

The data matrix (i.e., the raw data) contains the observed states. Because detection is imperfect, observed states can differ from the true state. An observation was given a 1 (observed state, species absent) if the species was not detected. If only adults were detected, then the observed state was 2 (observed state, species present but there is no breeding). If eggs or larvae were detected, this was noted as 3 (observed state, species present and breeding). The model uses this information to estimate the probability of detecting adults (but not breeding signs) and the probability of detecting breeding. These detection probabilities are then used to estimate the true (latent) states. For details on the model, see Nichols et al. (2007) and Kéry and Royle (2020, which includes code to fit the models to the data). Here, we only provide a description of the detection matrix in Table 1. It is important to note that the model differentiates between the true state of a population and the probability of detecting that true state. That is, it differentiates between the absence of breeding (i.e., absence of eggs or tadpoles) and non-detection of breeding (i.e., non-detection of eggs or tadpoles).

In a second analysis, we asked whether the state in the years 2011-2016 had an effect on occupancy in 2017-2018. For this analysis, we used data from all sites surveyed in 2011-2016 and 73 sites resurveyed in 2017 or 2018 (which were first surveyed in 2011 and 2012). The sites surveyed only once lead to greater precision of the estimates of the states of the sites in 2011 and 2012. For this analysis, we combined a multistate model and a two-state (species present or absent; MacKenzie et al. 2002) occupancy model. We first modeled the state in the years 2011 and 2012 using the multistate model. Then we used the estimated states as predictor variables for occupancy in the two-state occupancy model, using a single vague prior on detection probability across all sites in this second analysis (code for this latter model can be found in Kéry and Schaub [2011]).

We had no data on habitat characteristics that could be used in a reliable way to model occupancy or breeding probabilities (e.g., from remote sensing; Cruickshank et al. 2020; see also Appendix S1: Section S3). Therefore,

TABLE 1. Description of the detection matrix used in the multistate occupancy models.

\begin{tabular}{|c|c|c|c|}
\hline \multirow[b]{2}{*}{ True state } & \multicolumn{3}{|c|}{ Observed state } \\
\hline & Absent & $\begin{array}{c}\text { Species } \\
\text { present but } \\
\text { no breeding } \\
\text { detected }\end{array}$ & $\begin{array}{l}\text { Species } \\
\text { present and } \\
\text { breeding } \\
\text { detected }\end{array}$ \\
\hline Absent & 1 & 0 & 0 \\
\hline $\begin{array}{l}\text { Species } \\
\text { present, no } \\
\text { breeding }\end{array}$ & $1-p_{2,2}$ & $p_{2,2}$ & 0 \\
\hline $\begin{array}{l}\text { Species } \\
\text { present and } \\
\text { breeding }\end{array}$ & $1-p_{3,2}-p_{3,3}$ & $p_{3,2}$ & $p_{3,3}$ \\
\hline
\end{tabular}

Notes: The detection matrix is a $3 \times 3$ matrix in which rows represent the true states of the populations and columns represent the observed states. The parameter $p_{2,2}$ is the probability that a population that is in state "species present but there is no breeding" is detected (i.e., adults only); $p_{3,2}$ is the probability that only adults are detected in a population that is in state "species present and breeding"; $p_{3,3}$ is the probability that signs of breeding (eggs or larvae) are detected in a population that is in state "species present and breeding." The zeroes in the matrix indicate that model assumes that there are no false positives. The probabilities in a row sum to one. 
these parameters, as well as detection probabilities for each state were modeled as constant.

Some species have restricted ranges in Switzerland and occur only in southern Switzerland (Hyla intermedia, Rana latastei, Triturus carnifex). For these species, we used only the sites from this region in the analysis.

All models were run in JAGS (Plummer 2003) using the R package jagsUI (Kellner 2016). All models were run using a burn-in of 5,000, three chains, and thinning 1 in 10, with 50,000 iterations. Convergence was assessed using the Brooks-Gelman-Rubin statistic (Kéry and Schaub 2011). We used uninformative priors for all parameters (based on the code in Kéry and Schaub (2011) and Kéry and Royle (2020)).

\section{RESUlts}

\section{Detection probability}

Species were easier to detect in sites in which they did breed than in sites in which they did not breed $\left(p_{3,2}+\right.$ $p_{3,3}>p_{2,2}$; Fig. 1). The probability that breeding signs were detected $\left(p_{3,3}\right)$ was low for most species and for many species substantially lower than the probability of detecting only adults in breeding populations $\left(p_{3,2}\right.$; Fig. 1). The exceptions were Alytes obstetricans, Bufo bufo, and Epidalea calamita as well as the Rana frogs. The latter probably had very high detection probabilities for breeding signs because they are mostly detected through egg masses (while adults can be hard to detect because males call underwater).

\section{Breeding probability}

The multistate model showed that breeding probabilities were substantially lower than 1 (Fig. 2). For most species, the ratio of breeding to non-breeding populations was between 3:1 and 5:1 (Fig. 3). However, there were species where there were only few non-breeding populations (e.g., Rana temporaria, Ichthyosaura alpestris) while for other species (e.g., Hyla arborea, Triturus cristatus) the majority of sites had non-breeding populations. The $95 \%$ credible intervals for the number of nonbreeding populations were often wide, particularly for species that were either rare (e.g., R. latastei) or have low detection probabilities (L. vulgaris).

\section{The effect of breeding state upon subsequent occupancy}

Population status during the years 2011-2016 (absent, present but no breeding, present and breeding) had a strong effect on occupancy in 2017-2018 (Fig. 4). The results, however, have to be interpreted cautiously because the number of sites included in this analysis is small and therefore $95 \%$ credible intervals are wide. Across all species, colonizations were observed (i.e., some sites that were unoccupied in 2011-2012 were occupied in 2017 or 2018, Fig. 4, bars labelled
"Unoccupied"). With the exception of $H$. arborea, populations of all species in state "present but not breeding" in 2011-2012 had lower occupancy probabilities in 2017-2018 than populations in state "present and breeding," indicating that populations where breeding occurred were more likely to persist.

\section{Discussion}

The analysis of breeding probabilities in an assemblage of amphibians based on data from a national monitoring program revealed that there is no breeding in many amphibian populations (Figs. 2, 3), that nonbreeding populations are less likely to persist than breeding populations (Fig. 4), and that non-breeding populations are harder to detect than breeding populations (Fig. 1). A particularly striking case is the tree frog $H$. arborea where only one-quarter of the populations seem to be breeding populations (i.e., eggs and tadpoles were absent from most sites). Because the data were collected at a large number of sites and over more than half a decade, results are unlikely to be caused by a single year with unfavorable conditions, lending confidence to our results.

Reproductive success varies among years in amphibian populations (Shoop 1974, Bell and Lawton 1975, Sinsch 1992, Green et al. 2013, Greenberg et al. 2017) and many populations are apparently sink populations with insufficient reproduction to persist without immigration (Gill 1978, Sinsch 1992, Hels 2002), perhaps because of low habitat quality (Sjögren 1991, Unglaub et al. 2015, Gould et al. 2019, Schmidt et al. 2019). Our results show that breeding probabilities are substantially smaller than one and we show that in a country where declines of rare and common species have been reported (Cruickshank et al. 2016, Petrovan and Schmidt 2016), there are a number of species for which non-breeding populations outnumber breeding populations. Whether a population was breeding or non-breeding was related to persistence (Fig. 4), corroborating the qualitatively similar results of Green et al. (2013) and Tournier et al. (2017). Breeding populations were less likely to go extinct than non-breeding populations. Moreover, nonbreeding populations had lower detection probabilities than breeding populations. Low detection probability can indicate higher extinction risk (Alpizar-Jara et al. 2004) because detectability is often correlated to population size (Tanadini and Schmidt 2011), further suggesting that the population is at risk (i.e., less likely to persist).

One might expect that species breeding in temporary ponds may be less affected by low breeding probabilities because they are adapted to intermittent breeding success (e.g., through bet-hedging life history strategies involving longer lifespans and reduced annual investment into reproduction; Wilbur and Rudolf 2006). Population models suggest that temporary-pond breeding species can persist despite the absence of reproduction in 

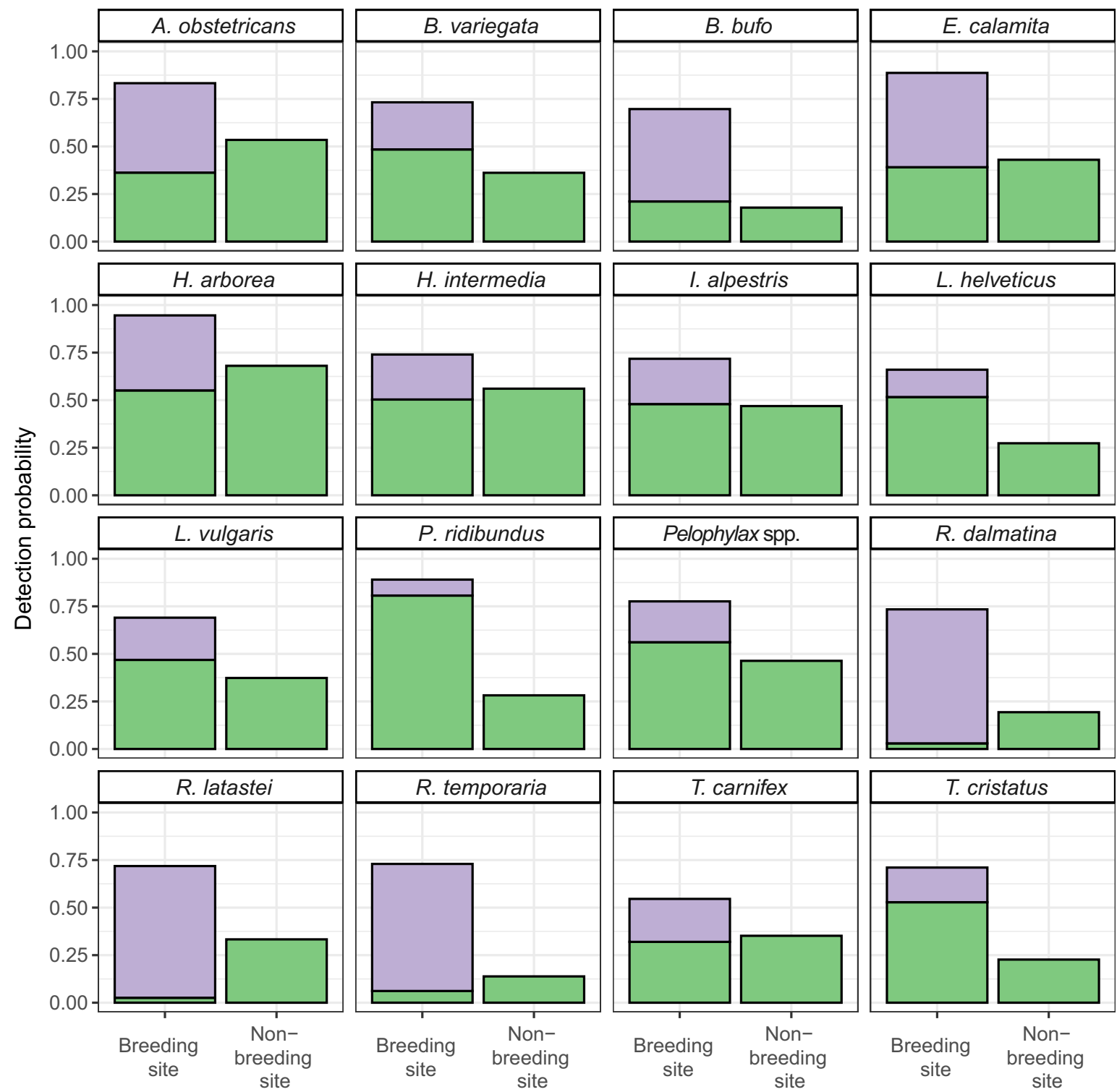

\section{Life stages detected}

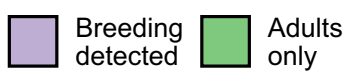

FIG. 1. The probability of detections at breeding sites and non-breeding sites. Green bars denote the detection of adults (and no breeding signs), purple bars denote detections that include the detection of breeding signs. The total height of the bars gives the overall probability that the species is identified at breeding or non-breeding sites. Bars show posterior means. Estimates shown are for the WBS data set 2011-2016. The estimates and the 95\% credible intervals are also presented in Appendix S1: Fig. S1. Genera are Alytes (A. obstetricans), Bombina (B. variegata), Bufo (B. bufo), Epidalea (E. calamita), Hyla (H. arborea, H. intermedia), Ichthyosaura (I. alpestris), Lissotriton (L. helveticus, L. vulgaris), Pelophylax (P. ridibundus), Rana (R. dalmatina, R. latastei, R. temporaria), and Triturus (T. cristatus, T. carnifex).

some years as long as the frequency of "bad" years does not increase too much (Stevens and Baguette 2008). However, a difference in breeding probabilities between species preferring different pond hydroperiod lengths was not clearly supported by the data. This can be seen by comparing the species that are typical temporarypond breeding species (E. calamita, B. variegata, and
H. arborea) to the other species that are more likely to breed in permanent ponds (Van Buskirk 2003). The results in Fig. 4 therefore suggest that a preference for short or long hydroperiods does not appear to predict breeding probabilities. It would be important to assess the relationship between the viability of a metapopulation and the proportion of populations in a 


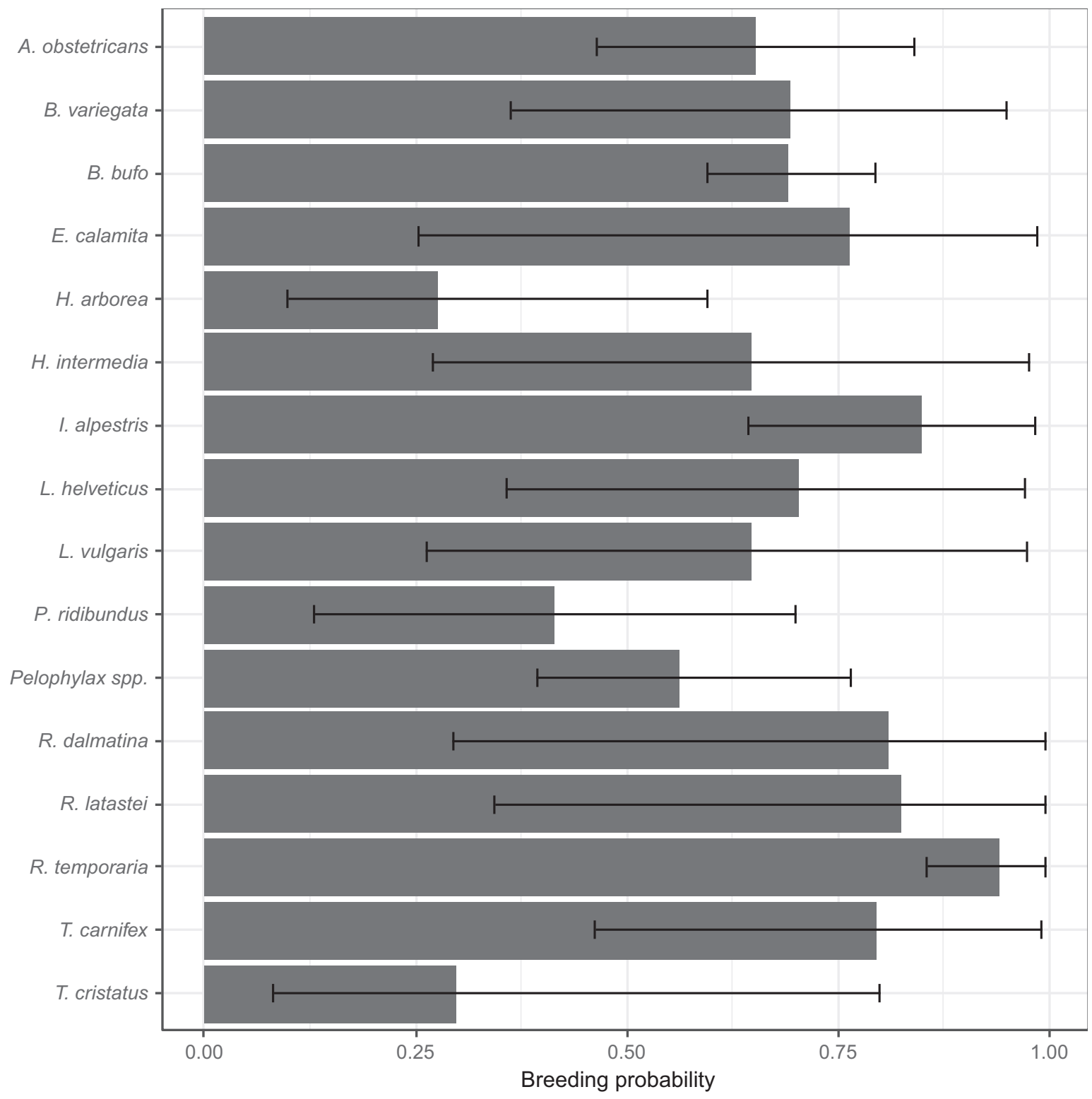

FIG. 2. Estimates of breeding probabilities. The bars show posterior means. Error bars show $95 \%$ credible intervals.

metapopulation network that produce offspring. Green and Bailey (2015) found that a metapopulation of the Wood frog Lithobates sylvatica was viable if $>16 \%$ of the populations produce offspring. Unfortunately, similar analyses do not exist for the species that we studied. Furthermore, it would be worthwhile to study how often populations transition between the states "breeding population" to "non-breeding population" because this determines their functional importance in a metapopulation network (Peterman et al. 2018, Gould et al. 2019). Ideally, such an analysis should also include an assessment of structural and functional connectivity (Semlitsch 2000, Baguette et al. 2013, Cruickshank et al. 2020).
Low breeding probabilities may affect metapopulations dynamics through changes in connectivity. Connectivity is known to affect patch occupancy in amphibian populations because many populations depend on immigration (Sjögren 1991, Sinsch 1992, Cruickshank et al. 2020). Immigration depends, amongst other things, on the number of emigrants produced by neighboring populations (Hanski 1994). Commonly used metapopulation connectivity metrics are thought to reflect this number and are pragmatically calculated using the distance between sites and the size (area) of the sites. The size of a patch is thought to reflect the number of emigrants (Hanski 1994). However, when only a subset of populations are breeding populations, connectivity measures that 

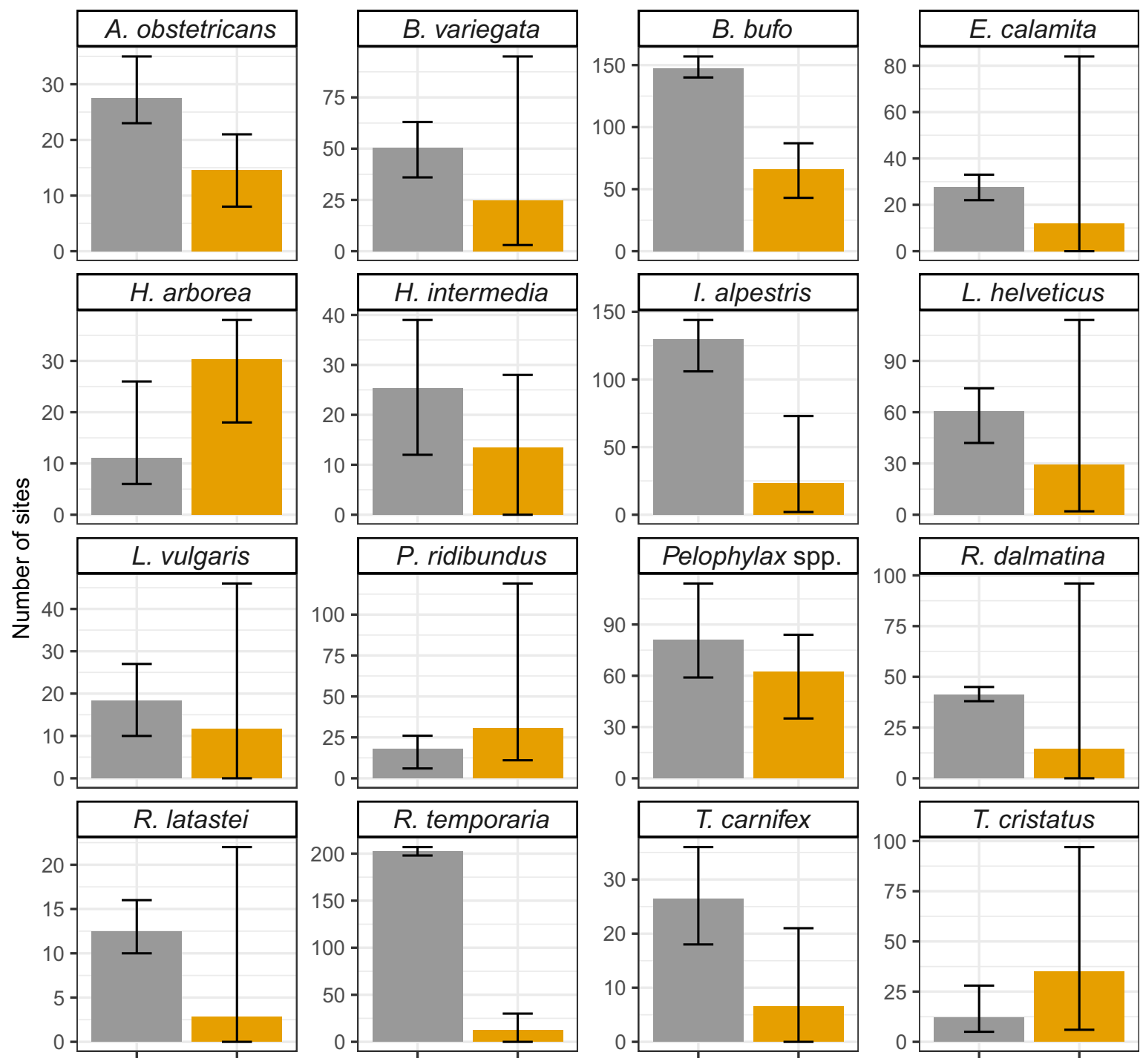

Breeding

Not breeding

FIG. 3. The numbers of occupied sites at which breeding is occurring and in which the species is present but no breeding is occurring, within the WBS data set (years 2011-2016). The colored bars show posterior means. Error bars are $95 \%$ credible intervals.

acknowledge that non-breeding populations do not produce dispersing individuals should be preferred. Assuming that non-breeding populations produce no emigrants, one might thus add an indicator variable to the equation that states whether a population is a breeding or a non-breeding population (e.g., one and zero). Such a change would be easy to implement and Hamer and Mahony (2010) showed that such a modeling approach can predict occupancy and turnover of amphibians. Ideally, such an approach should be combined with recent improvements in the estimation of connectivity in metapopulations where the number of dispersers is estimated from data (Sutherland et al. 2012, Howell et al. 2018, Duarte et al. 2020). For example, Howell et al.
(2020) modeled the probability of immigration, $\pi$, between the focal pond $i$ and the neighboring pond $m$ as $\pi_{i, m}=\exp \left(-\rho \times d_{i, m}\right)$, where $\rho$ describes how the dispersal probability declines with distance and $d$ is the distance between ponds $i$ and $m$. This equation might be expanded to $\pi_{i, m}=\exp \left(-\rho \times d_{i, m} \times b\right)$, where $b$ is an indicator of breeding that equals 1 if pond $m$ is a breeding population and 0 if it is a non-breeding population. Modeling connectivity and the number of dispersers in such a way and might lead to more realistic estimates of connectivity and might explain why connectivity is sometimes found to be unimportant for amphibian metapopulation dynamics (Marsh and Trenham 2001, Prugh et al. 2008). Moreover, distance $d$ between ponds may further include 


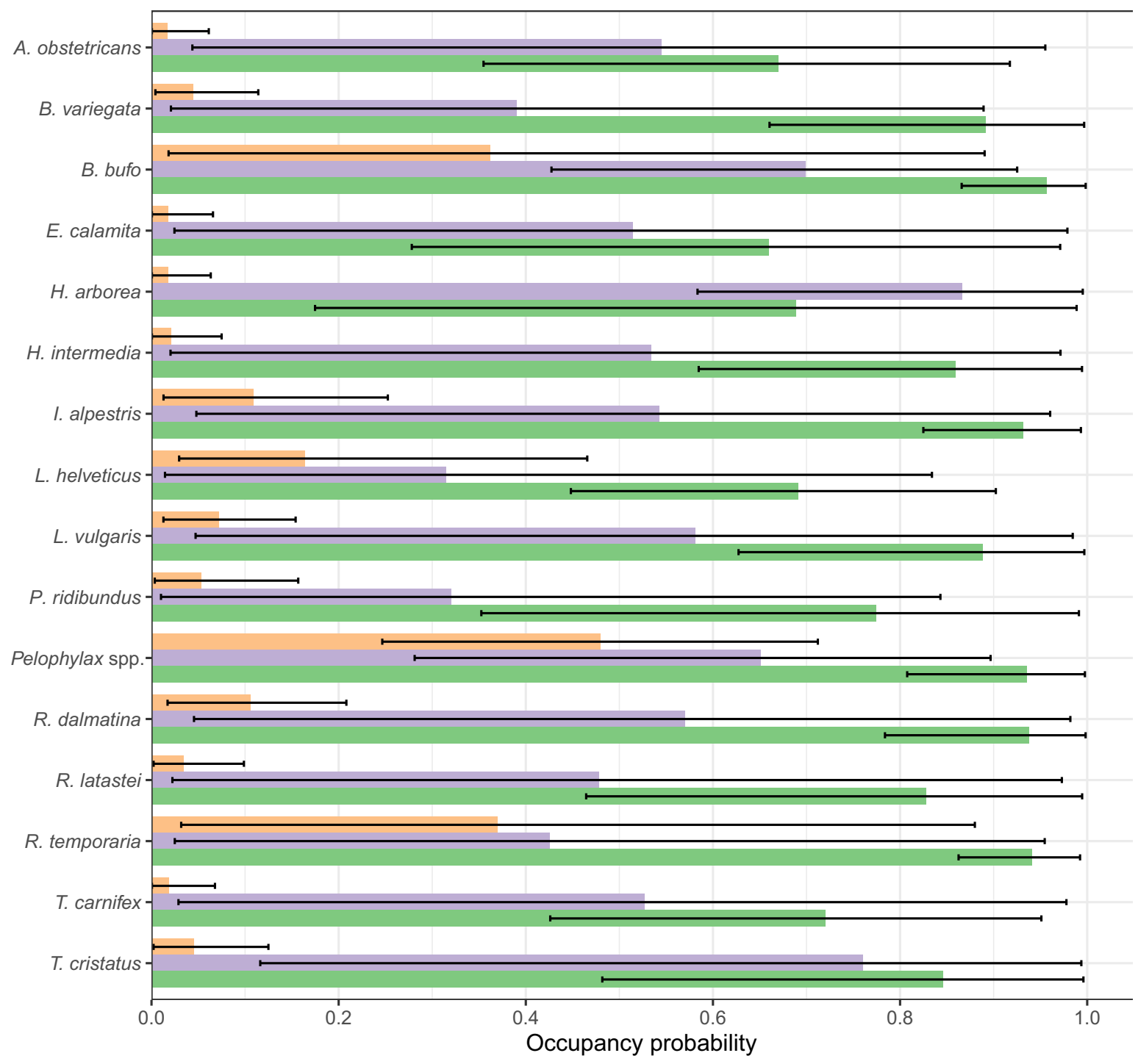

Unoccupied

Non-breeding

Breeding

FIG. 4. Effect of breeding status in the first round of surveys (absent, present but no breeding, present and breeding) upon the occupancy status of sites in the second round of surveys (absent, present).

information on the landscape resistance to colonization (Howell et al. 2018).

It would be important to understand the reasons why breeding probabilities are low. Lacking biologically relevant data, we could not undertake an analysis of the determinants of breeding probability, but such an analysis would clearly be worthwhile. In particular, joint analyses of habitat and occupancy dynamics might prove valuable (Miller et al. 2012, Gould et al. 2019). Predictor variables of particular interest would include habitat quality (Unglaub et al. 2015, Schmidt et al. 2019), invasive species (Miller et al. 2012, Manenti et al. 2020), and population size (e.g., Allee and density dependent effects; Cayuela et al. 2019, Boualit et al. 2020). Furthermore, one might also partition breeding probability into the probabilities that eggs, larvae and/or metamorphs are present (Green et al. 2013) and link these probabilities to explanatory variables. Ultimately, one should use estimates of breeding probabilities to determine the contribution of populations to the metapopulation and whether they should be classified as sources or sinks (Runge et al. 2006).

We suggest that breeding probabilities should be regularly assessed because they affect occupancy dynamics. Distinguishing between breeding and non-breeding populations contributes to a more mechanistic 
understanding of occupancy dynamics and thereby increases the value of a monitoring program that tracks these dynamics. Importantly, recording the observation of eggs and larvae in our monitoring program did not lead to additional costs because these life stages could be detected while looking for adults. However, the $95 \%$ credible intervals of occupancy and detectability parameters were wide. This was partly because the number of species occurrences was low. This is known to lead to imprecise estimates, particularly in multistate models (Kéry and Royle 2020). The precision of estimates would increase with higher detection probabilities. Green et al. (2013), for example, reported for wood frogs high detection probabilities of eggs and tadpoles of 0.94 and 0.96 , respectively. Detection probabilities were much lower in our study but could be increased if surveyors were instructed to search more intensively for eggs, larvae, and possibly metamorphs. This might increase costs, however.

An unexpected result with implications for monitoring was that detection probabilities for non-breeding populations were low (Fig. 3). As discussed above, low detection probabilities may be caused by small population size (Tanadini and Schmidt 2011). Low detection probabilities imply that many non-breeding populations may have been overlooked. For example, a non-breeding population of the common frog $R$. temporaria had a detection probability of 0.14 . Thus, the cumulative detection probability after four site visits is 0.45 , suggesting that many non-breeding populations were missed. Therefore, additional site visits may be necessary to detect nonbreeding populations (Tanadini and Schmidt 2011). Detection of non-breeding populations would be important because extinction risk could be decreased through species-specific habitat management.

The monitoring of breeding probabilities has applications beyond occupancy and trend estimation. Issues in conservation biology such as the success of invasive species could be traced with such data. For example, T. carnifex had higher breeding probabilities than $T$. cristatus (Fig. 1) and the former is invasive in some areas in northern Switzerland and has supplanted the native T. cristatus (Dufresnes et al. 2016). A higher breeding propensity may have contributed to propagule pressure and to the spread of this invasive species.

Although we began the discussion with the statement that the absence of reproduction in many amphibian populations is a reason for concern, we want to end the discussion with a positive message for amphibian conservation. Lack of breeding is a conservation problem that is actionable because the probability of breeding can be quantified through monitoring programs and because breeding probabilities can be increased through pond management, possibly using adaptive management (Canessa et al. 2019) or based on the knowledge compiled in the conservation evidence data base (Smith and Sutherland 2014). For example, breeding may be restored through the removal of nonnative fish
(Vredenburg 2004) or ponds with hydroperiods that maximize reproductive success can be constructed (Schmidt et al. 2015). If we focus on problem solving, then conservation action may lead to the recovery of amphibian populations despite the many gloomy reports of worldwide declines (Grant et al. 2019).

\section{ACKNOWLEDGMENTS}

We thank the field surveyors for collecting the data and Erin Muths and the reviewers for comments on the manuscript. This research project was supported through a grant from the Swiss Federal Office for the Environment (contract 00.5062.PZ/R4851423).

\section{Literature Cited}

Alpizar-Jara, R., J. D. Nichols, J. E. Hines, J. R. Sauer, K. H. Pollock, and C. S. Rosenberry. 2004. The relationship between species detection probability and local extinction probability. Oecologia 141:652-660.

Bacon, L., Y. Hingrat, F. Jiguet, A. C. Monnet, F. Sarrazin, and A. Robert. 2017. Habitat suitability and demography, a timedependent relationship. Ecology and Evolution 7:2214-2222.

Baguette, M., S. Blanchet, D. Legrand, V. M. Stevens, and C. Turlure. 2013. Individual dispersal, landscape connectivity and ecological networks. Biological Reviews 88:310-326.

Bell, G., and J. H. Lawton. 1975. The ecology of the eggs and larvae of the smooth newt (Triturus vulgaris (Linn.)). Journal of Animal Ecology 44:393-423.

Bergamini, A., et al. 2019. Zustand und Entwicklung der Biotope von nationaler Bedeutung: Resultate 2011-2017 der Wirkungskontrolle Biotopschutz Schweiz. WSL Berichte 85:1-104.

Bjørnstad, O. N., and B. T. Grenfell. 2001. Noisy clockwork: Time series analysis of population fluctuation in animals. Science 293:638-643.

Boualit, L., J. Pichenot, A. Besnard, R. Helder, P. Joly, and H. Cayuela. 2020. Environmentally mediated reproductive success predicts breeding dispersal decisions in an early successional amphibian. Animal Behaviour 149:107-120.

Brambilla, M., and G. F. Ficetola. 2012. Species distribution models as a tool to estimate reproductive parameters: a case study with a passerine bird species. Journal of Animal Ecology 81:781-787.

Buckland, S. T., A. E. Magurran, R. E. Green, and R. M. Fewster. 2005. Monitoring change in biodiversity through composite indices. Philosophical Transactions of the Royal Society B 360:243-254.

Canessa, S., D. Ottonello, G. Rosa, S. Salvidio, E. Grasselli, and F. Oneto. 2019. Adaptive management of species recovery programs: A real-world application for an endangered amphibian. Biological Conservation 236: 202-210.

Cayuela, H., B. R. Schmidt, A. Weinbach, A. Besnard, and P. Joly. 2019. Multiple density-dependent processes shape the dynamics of a spatially structured amphibian population. Journal of Animal Ecology 88:164-177.

Clements, C. F., and A. Ozgul. 2016. Including trait-based early warning signals helps predict population collapse. Nature Communications 7:10984.

Clutton-Brock, T., and B. C. Sheldon. 2010. Individuals and populations: the role of long-term, individual-based studies of animals in ecology and evolutionary biology. Trends in Ecology and Evolution 25:562-573. 
Coulson, T., B. E. Kendall, J. Barthold, F. Plard, S. Schindler A. Ozgul, and J.-M. Gaillard. 2017. Modeling adaptive and nonadaptive responses of populations to environmental change. American Naturalist 190:313-336.

Cruickshank, S., A. Bergamini, and B. R. Schmidt. 2021. Data from: Estimation of breeding probbability can make monitoring data more revealing: a case study of amphibians. EnviDat. https://doi.org/10.16904/envidat.216

Cruickshank, S. S., A. Ozgul, S. Zumbach, and B. R. Schmidt. 2016. Quantifying population declines based on presenceonly records for Red List assessments. Conservation Biology 30:1112-1121.

Cruickshank, S. S., B. R. Schmidt, C. Ginzler, and A. Bergamini. 2020. Local habitat measures derived from aerial pictures are not a strong predictor of amphibian occurrence and abundance. Basic and Applied Ecology 45:51-61.

Dodd, C. K. Jr editor. 2009. Amphibian ecology and conservation: a handbook of techniques. Oxford University Press, Oxford, UK.

Duarte, A., J. T. Peterson, C. A. Pearl, J. C. Rowe, B. McCreary, S. K. Galvan, and M. J. Adams. 2020. Estimation of metademographic rates and landscape connectivity for a conservation-reliant anuran. Landscape Ecology 35:1459-1479.

Dufresnes, C., J. Pellet, S. Bettinelli-Riccardi, J. Thiébaud, N. Perrin, and L. Fumagalli. 2016. Massive genetic introgression in threatened northern crested newts (Triturus cristatus) by an invasive congener (T. carnifex) in Western Switzerland Conservation Genetics 17:839-846.

Falaschi, M., R. Manenti, W. Thuiller, and G. F. Ficetola. 2019. Continental-scale determinants of population trends in European amphibians and reptiles. Global Change Biology 25:3504-3515

Geijzendorffer, I. R., et al. 2016. Bridging the gap between biodiversity data and policy reporting needs: An Essential Biodiversity Variables perspective. Journal of Applied Ecology 53:1341-1350.

Gill, D. E. 1978. The metapopulation ecology of the red-spotted newt, Notophthalmus viridescens (Rafinesque). Ecological Monographs 48:145-166.

Gould, W. R., A. M. Ray, L. L. Bailey, D. Thoma, R. Daley, and K. Legg. 2019. Multistate occupancy modeling improves understanding of amphibian breeding dynamics in the Greater Yellowstone Area. Ecological Applications 29: e01825.

Grant, E. H. C., et al. 2016. Quantitative evidence for the effects of multiple drivers on continental-scale amphibian declines. Scientific Reports 6:25625.

Grant, E. H. C., E. Muths, B. R. Schmidt, and S. O. Petrovan 2019. Amphibian conservation in the Anthropocene. Biological Conservation 236:543-547.

Green, A. W., and L. L. Bailey. 2015. Using Bayesian population viability analysis to define relevant conservation objectives. PLoS ONE 10:e0144786.

Green, A. W., M. B. Hooten, E. H. C. Grant, and L. L. Bailey 2013. Evaluating breeding and metamorph occupancy and vernal pool management effects for wood frogs using a hierarchical model. Journal of Applied Ecology 50:1116-1123.

Greenberg, C. H., S. J. Zarnoch, and J. D. Austin. 2017. Weather, hydroregime, and breeding effort influence juvenile recruitment of anurans: implications for climate change. Ecosphere 8:e01789.

Gurevitch, J., G. A. Fox, N. L. Fowler, and C. H. Graham. 2016. Landscape demography: population change and its drivers across spatial scales. Quarterly Review of Biology 91:459-485.
Hamer, A. J., and M. J. Mahony. 2010. Rapid turnover in site occupancy of a pond-breeding frog demonstrates the need for landscape-level management. Wetlands 30:287-299.

Hanski, I. 1994. A practical model of metapopulation dynamics. Journal of Animal Ecology 63:151-162.

Hels, T. 2002. Population dynamics in a Danish metapopulation of spadefoot toads Pelobates fuscus. Ecography 25:303-313.

Houlahan, J. E., C. S. Findlay, B. R. Schmidt, A. H. Meyer, and S. L. Kuzmin. 2000. Quantitative evidence for global amphibian population declines. Nature 404:752-755.

Howell, P. E., B. R. Hossack, E. Muths, B. H. Sigafus, and R. B. Chandler. 2020. Informing amphibian conservation efforts with abundance-based metapopulation models. Herpetologica 76:240-250.

Howell, P. E., E. Muths, B. R. Hossack, B. H. Sigafus, and R. B. Chandler. 2018. Increasing connectivity between metapopulation ecology and landscape ecology. Ecology 99:1119-1128.

Inchausti, P., and J. Halley. 2003. On the relation between temporal variability and persistence time in animal populations. Journal of Animal Ecology 72:899-908.

Jetz, W., et al. 2019. Essential biodiversity variables for mapping and monitoring species populations. Nature Ecology \& Evolution 3:539-551.

Kearney, M. 2006. Habitat, environment and niche: what are we modelling? Oikos 115:186-191.

Keith, D. A., H. R. Akcakaya, W. Thuiller, G. F. Midgley, R. G. Pearson, S. J. Phillips, H. M. Regan, M. B. Araujo, and T. G. Rebelo. 2008. Predicting extinction risks under climate change: coupling stochastic population models with dynamic bioclimatic habitat models. Biology Letters 4:560-563.

Kellner, K. 2016. jagsUI: A wrapper around 'rjags' to streamline 'JAGS' analyses. R package Version 1.4.2. R Foundation for Statistical Computing, Vienna, Austria. http://CRAN.Rproject.org/package=jagsUI

Kéry, M., G. Guillera-Arroita, and J. J. Lahoz-Monfort. 2013. Analysing and mapping species range dynamics using occupancy models. Journal of Biogeography 40: 1463-1474.

Kéry, M., and J. A. Royle 2020. Applied hierarchical modeling in ecology: dynamic and advanced models, Volume 2. Academic Press, San Diego, California, USA.

Kéry, M., and M. Schaub 2011. Bayesian population analysis using WinBUGS. Academic Press, San Diego, California, USA.

Leung, B., D. A. Greenberg, and D. M. Green. 2017. Trends in mean growth and stability in temperate vertebrate populations. Diversity and Distributions 23:1372-1380.

MacKenzie, D. I., J. D. Nichols, J. E. Hines, M. G. Knutson, and A. B. Franklin. 2003. Estimating site occupancy, colonization, and local extinction when a species is detected imperfectly. Ecology 84:2200-2207.

MacKenzie, D. I., J. D. Nichols, G. B. Lachman, S. Droege, J. A. Royle, and C. A. Langtimm. 2002. Estimating site occupancy rates when detection probabilities are less than one. Ecology 83:2248-2255.

Manenti, R., M. Falaschi, D. Delle Monache, S. Marta, and G. F. Ficetola. 2020. Network-scale effects of invasive species on spatially-structured amphibian populations. Ecography 43:119-127.

Marsh, D. M., and P. C. Trenham. 2001. Metapopulation dynamics and amphibian conservation. Conservation Biology 15:40-49.

Marsh, D. M., and P. C. Trenham. 2008. Current trends in plant and animal population monitoring. Conservation Biology 22:647-655. 
Martin, J., C. L. McIntyre, J. E. Hines, J. D. Nichols, J. A. Schmutz, and M. C. MacCluskie. 2009. Dynamic multistate site occupancy models to evaluate hypotheses relevant to conservation of Golden Eagles in Denali National Park, Alaska. Biological Conservation 142:2726-2731.

McDonald, T. L. 2003. Review of environmental monitoring methods: survey designs. Environmental Monitoring and Assessment 85:277-292.

Miller, D. A. W., C. S. Brehme, J. E. Hines, J. D. Nichols, and R. N. Fisher. 2012. Joint estimation of habitat dynamics and species interactions: disturbance reduces co-occurrence of non-native predators with an endangered toad. Journal of Animal Ecology 81:1288-1297.

Muths, E., et al. 2017. Heterogeneous responses of temperatezone amphibian populations to climate change complicates conservation planning. Scientific Reports 7:17102.

Nichols, J. D., J. E. Hines, J.-D. Lebreton, and R. Pradel. 2000. Estimation of contributions to population growth: a reverse-time capture-recapture approach. Ecology 81:3362-3376.

Nichols, J. D., J. E. Hines, D. I. MacKenzie, M. E. Seamans, and R. J. Gutierrez. 2007. Occupancy estimation and modeling with multiple states and state uncertainty. Ecology 88:1395-1400.

Nichols, J. D., and B. K. Williams. 2006. Monitoring for conservation. Trends in Ecology and Evolution 21:668-673.

Peterman, W. E., T. L. Anderson, B. H. Ousterhout, D. L. Drake, J. J. Burkhart, F. Rowland, and R. D. Semlitsch. 2018. Using spatial demographic network models to optimize habitat management decisions. Journal of Wildlife Management 82:649-659.

Petrovan, S. O., and B. R. Schmidt. 2016. Volunteer conservation action data reveals large-scale and long-term negative population trends of a widespread amphibian, the common toad (Bufo bufo). PLoS ONE 11:e0161943.

Plard, F., D. Turek, M. U. Grüebler, and M. Schaub. 2019. IPM2: toward better understanding and forecasting of population dynamics. Ecological Monographs 89:e01364.

Plummer, M. 2003. JAGS: A program for analysis of Bayesian graphical models using Gibbs sampling. Proceedings of the 3rd International Workshop on Distributed Statistical Computing 124:1-10.

Prugh, L. R., K. E. Hodges, A. R. E. Sinclair, and J. Brashares. 2008. Effect of habitat area and isolation on fragmented animal populations. Proceedings of the National Academy of Sciences USA 105:20770-20775.

Pulliam, H. R. 1988. Sources, sinks, and population regulation. American Naturalist 132:652-661.

Pulliam, H. R. 2000. On the relationship between niche and distribution. Ecology Letters 3:349-361.

Runge, J. P., M. C. Runge, and J. D Nichols. 2006. The role of local populations within a landscape context: defining and classifying sources and sinks. American Naturalist 167:925-938.

Schmeller, D. S., et al. 2018. A suite of essential biodiversity variables for detecting critical biodiversity change. Biological Reviews 93:55-71.

Schmidt, B. R., R. Arlettaz, M. Schaub, B. Lüscher, and M. Kröpfli. 2019. Benefits and limits of comparative effectiveness studies in evidence-based conservation. Biological Conservation 236:115-123.

Schmidt, B. R., R. Feldmann, and M. Schaub. 2005. Demographic processes underlying population growth and decline in Salamandra salamandra. Conservation Biology 19:1149-1156.

Schmidt, B. R., and J. Pellet. 2005. Relative importance of population processes and habitat characteristics in determining site occupancy of two anurans. Journal of Wildlife Management 69:884-893.

Schmidt, B. R., and S. Zumbach. 2019. Amphibian conservation in Switzerland. Pages 46-51 in H. Heatwole and J. W. Wilkinson, editors. Amphibian biology: status of conservation and decline of amphibians, Eastern Hemisphere, Part 5, Northern Europe, Volume 11. Pelagic Publishing, Exeter, UK.

Schmidt, B. R., S. Zumbach, U. Tobler, and M. Lippuner. 2015. Amphibien brauchen temporäre Gewässer. Zeitschrift für Feldherpetologie 22:137-150.

Searcy, C. A., and H. B. Shaffer. 2016. Do ecological niche models accurately identify climatic determinants of species ranges? American Naturalist 187:423-435.

Semlitsch, R. D. 2000. Principles for management of aquaticbreeding amphibians. Journal of Wildlife Management 64:615-631.

Shoop, C. R. 1974. Yearly variation in larval survival of Ambystoma maculatum. Ecology 55:440-444.

Sinsch, U. 1992. Structure and dynamic of a natterjack toad metapopulation (Bufo calamita). Oecologia 90:489-499.

Sjögren, P. 1991. Extinction and isolation gradients in metapopulations: the case of the pool frog (Rana lessonae). Biological Journal of the Linnean Society 42:135-147.

Smith, R. K., and W. J. Sutherland 2014. Amphibian conservation: global evidence for the effects of interventions. Pelagic Publishing, Exeter, UK.

Stevens, V. M., and M. Baguette. 2008. Importance of habitat quality and landscape connectivity for the persistence of endangered natterjack toads. Conservation Biology 22:1194-1204.

Stuart, S. N., J. S. Chanson, N. A. Cox, B. E. Young, A. S. L. Rodrigues, D. L. Fischman, and R. W. Waller. 2004. Status and trends of amphibian declines and extinctions worldwide. Science 306:1783-1786.

Sutherland, C., D. A. Elston, and X. Lambin. 2012. Multi-scale processes in metapopulations: contributions of stage structure, rescue effect, and correlated extinctions. Ecology 93:2465-2473.

Tanadini, L. G., and B. R. Schmidt. 2011. Population size influences amphibian detection probability: implications for biodiversity monitoring programs. PLoS ONE 6: e28244.

Thuiller, W., et al. 2014. Does probability of occurrence relate to population dynamics? Ecography 37:1155-1166.

Titeux, N., M. Dufrene, J. Radoux, A. H. Hirzel, and P. Defourny. 2007. Fitness-related parameters improve presence-only distribution modelling for conservation practice: The case of the red-backed shrike. Biological Conservation 138:207-223.

Tournier, E., A. Besnard, V. Tournier, and H. Cayuela. 2017. Manipulating waterbody hydroperiod affects movement behaviour and occupancy dynamics in an amphibian. Freshwater Biology 62:1768-1872.

Turchin, P. 1999. Population regulation: a synthetic view. Oikos 84:153-159.

Unglaub, B., S. Steinfartz, A. Drechsler, and B. R. Schmidt. 2015. Linking habitat suitability to demography in a pondbreeding amphibian. Frontiers in Zoology 12:9.

Unglaub, B., S. Steinfartz, D. Kühne, A. Haas, and B. R. Schmidt. 2018. The relationships between habitat suitability, population size and body condition in a pondbreeding amphibian. Basic and Applied Ecology 27:20-29.

Van Buskirk, J. 2003. Habitat partitioning in European and North American pond-breeding frogs and toads. Diversity and Distributions 9:399-410. 
Vredenburg, V. T. 2004. Reversing introduced species effects: Experimental removal of introduced fish leads to rapid recovery of a declining frog. Proceedings of the National Academy of Sciences USA 101:7646-7650.

Wilbur, H. M., and V. H. W. Rudolf. 2006. Life-history evolution in uncertain environments: bet hedging in time. American Naturalist 168:398-411.
Yackulic, C. B., J. D. Nichols, J. Reid, and R. Der. 2015. To predict the niche, model colonization and extinction. Ecology 96:16-23.

Zipkin, E. F., J. T. Thorson, K. See, H. J. Lynch, E. H. C. Grant, Y. Kanno, R. B. Chandler, B. H. Letcher, and J. A. Royle. 2014. Modeling structured population dynamics using data from unmarked individuals. Ecology 95:22-29.

SUPPORTING INFORMATION

Additional supporting information may be found online at: http://onlinelibrary.wiley.com/doi/10.1002/eap.2357/full

Open ReseARCH

Data (Cruickshank et al. 2021) are available from EnviDat at https://doi.org/10.16904/envidat.216. 